\title{
A SIMPLE TITRATION METHOD FOR DETERMINING THE SPECIFIC GRAVITY ON ONE DROP OF URINE
}

\author{
BY \\ R. G. BOWLER \\ From the Pathological Laboratory, the Peace Memorial Hospital, Watford
}

(RECEIVED FOR PUBLICATION APRIL 11, 1951)

\begin{abstract}
Samples of urine which have been collected by ureteric catheterization are necessarily small in volume, often only a few drops. In order to determine the efficiency of kidney function it may be necessary to measure the specific gravity of these small samples, but it is impossible to use the hydrometer method, which requires a minimum of about $50 \mathrm{ml}$. of urine. Methods involving the suspension of drops of urine in solvents, which are immiscible with water, are a possible alternative. Dukes (1939) has described a method based on these principles, but it has some disadvantages. A drop of urine is added to a mixture of carbon tetrachloride and xylol, and the composition of the mixture is adjusted by adding one of the constituents until the drop of urine floats in an equilibrium position. The specific gravity of the mixture is then measured with a urinometer. This requires the use of large volumes of reference liquid, $50 \mathrm{ml}$., for each test, and errors may be introduced due to the fact that the slight solubility of water in the $50 \mathrm{ml}$. of liquid may appreciably alter the composition of the drop of urine. The method of Monroe and Hopper (1946) makes use of a series of standard mixtures of xylol and bromobenzene of known specific gravity. Drops of urine are added to these mixtures in turn until the equilibrium mixture is found. This method is open to the same possibility of error, due to the relatively large volume of reference liquid used, as is the first method. Several drops of urine are required for the test and may not always be available. There is also the disadvantage that it is necessary to keep a large number of standard mixtures.
\end{abstract}

\section{Experimental}

The principle of the proposed method is as follows. One drop of urine is placed in a standard, small volume of an immiscible, inert liquid which has a specific gravity slightly lower than the minimum value for urine. The drop will sink to the bottom of the liquid. A denser liquid is added from a microburette until a mixture is obtained in which the drop of urine floats in equilibrium. The volume of liquid added is used to obtain the specific gravity from a graph.

The reference liquids should have the following properties. They should be readily miscible with each other but have a low solubility for water. No chemical reaction should take place between the two liquids or the urine. The component liquids should be stable, chemically pure substances with constant specific gravities 
in order that the specific gravity of any mixture of known composition can be calculated. They must have suitable specific gravities to cover the extreme limits of that of urine, 1.000 to 1.050 . The lighter of the two liquids must have a specific gravity which is lower than that of any urine which may be submitted for testing so that the drop of urine will sink in it. There is no point in using a liquid with a specific gravity much below 1.000 , as the method would lose sensitivity. A value of about 0.995 would be suitable. The liquids used in the methods referred to above would not be satisfactory. Xylol is not a pure chemical substance but a mixture of three xylenes ; its composition, and hence its specific gravity, may vary in different batches, and this would interfere with the calibration. Moreover, xylol has too low a specific gravity, about 0.870 . A mixture of equal volumes of benzene and monochlorobenzene has a specific gravity of 0.992 , and this has been found to be satisfactory as the first reference liquid. These components are both readily obtainable pure and are perfectly stable. The other, denser reference liquid should not have too high a specific gravity. It can be seen in Fig. 1 that the liquids used in other methods, carbon tetrachloride and bromobenzene, have unnecessarily high specific gravities, 1.600 and 1.499 respectively. In order to get maximum sensitivity it is essential that

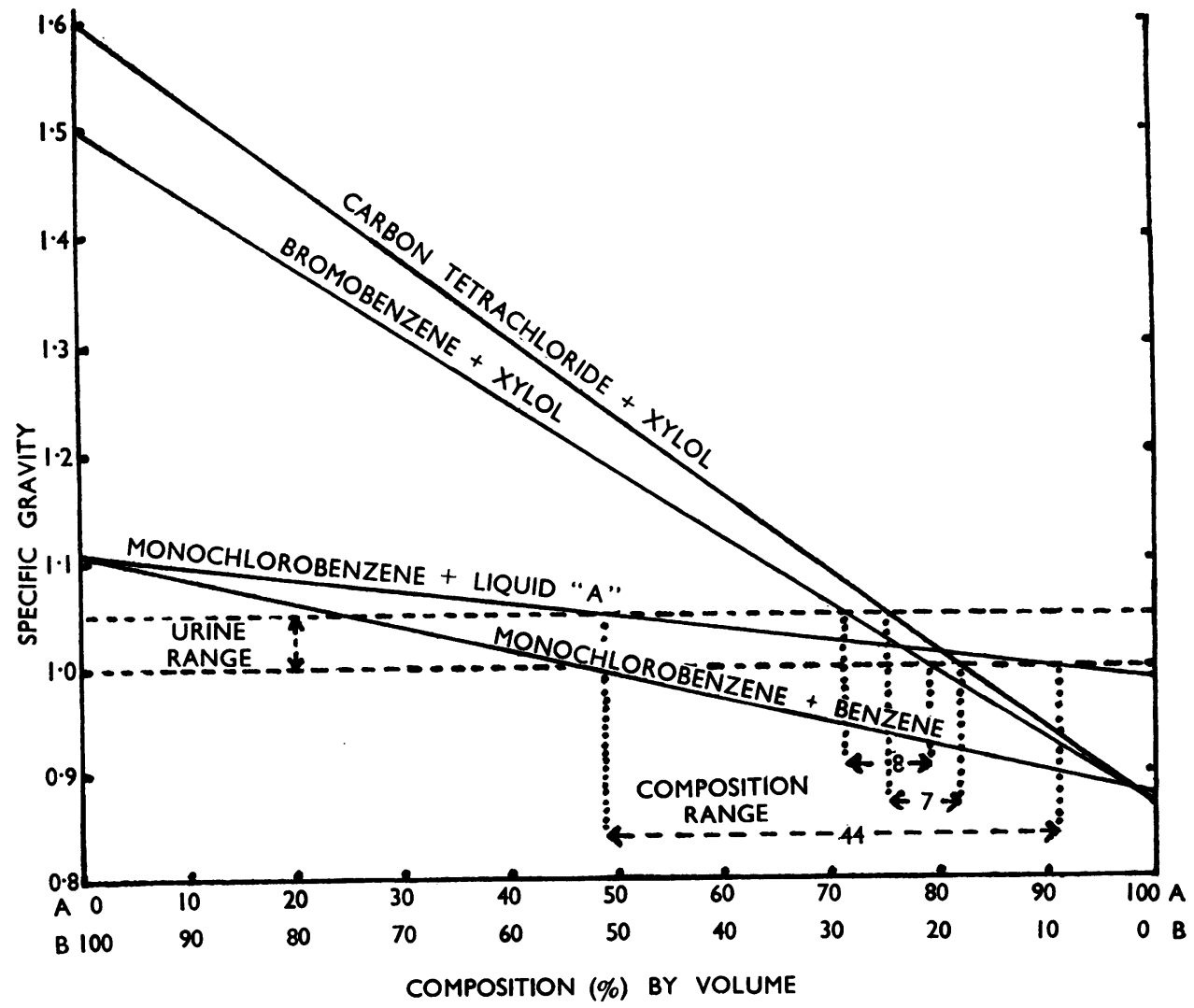

FIG. 1.-Graph of specific gravities of liquid mixtures of different composition. 
there should be a large change in the composition of the mixtures from a specific gravity of 1.000 to 1.050 . Monochlorobenzene, which has a specific gravity of 1.107 , has been found to be most suitable for this method.

\section{Method and Materials}

Materials.-The following materials are required.

Monochlorobenzene.- It should be pure, redistilled, and with a boiling point of $132^{\circ}$ C. and specific gravity of 1.107 .

Benzene.-Benzene should be pure, redistilled, with a boiling point of $80.1^{\circ} \mathrm{C}$. and a specific gravity of 0.879 .

Reference Liquid "A."-This should be of a specific gravity of 0.992 , prepared by mixing $50 \mathrm{ml}$. benzene with $50 \mathrm{ml}$. monochlorobenzene.

Calibration.-The composition of the mixtures obtained by adding different amounts of monochlorobenzene to $1 \mathrm{ml}$. of reference liquid "A" was calculated. The specific gravities of these mixtures were obtained from a graph. The results are given in Table I. The calibration curve was prepared by plotting a graph of the specific gravities of the mixtures against the volume of monochlorobenzene added (columns 6 and 2, Table I).

TABLE I

Composttion and Specific Gravities of Mixtures Obtained by Adding Different Amounts of Monochlorobenzene to One Millilitre LiQuid " A"

\begin{tabular}{|c|c|c|c|c|c|}
\hline $\begin{array}{c}\text { Volume of } \\
\text { Monochloro- } \\
\text { benzene in } \\
\text { One Millilitre } \\
\text { of Liquid " A " } \\
\text { (ml.) }\end{array}$ & $\begin{array}{l}\text { Volume of } \\
\text { Monochloro- } \\
\text { benzene } \\
\text { Added in } \\
\text { Titration } \\
\text { (ml.) }\end{array}$ & $\begin{array}{l}\text { Total } \\
\text { Volume of } \\
\text { Monochloro- } \\
\text { benzene } \\
\text { (ml.) }\end{array}$ & $\begin{array}{c}\text { Total } \\
\text { Volume of } \\
\text { Liquid } \\
\text { (ml.) }\end{array}$ & $\begin{array}{c}\text { Percentage } \\
\text { of } \\
\text { Monochloro- } \\
\text { benzene in } \\
\text { Mixture }\end{array}$ & $\begin{array}{l}\text { Specific } \\
\text { Gravity } \\
\text { of } \\
\text { Mixture }\end{array}$ \\
\hline $\begin{array}{l}0.5 \\
0.5 \\
0.5 \\
0.5 \\
0.5 \\
0.5 \\
0.5 \\
0.5 \\
0.5 \\
0.5 \\
0.5 \\
0.5 \\
0.5\end{array}$ & $\begin{array}{l}0.05 \\
0 \cdot 10 \\
0 \cdot 15 \\
0 \cdot 20 \\
0 \cdot 25 \\
0 \cdot 30 \\
0 \cdot 40 \\
0 \cdot 50 \\
0 \cdot 60 \\
0 \cdot 70 \\
0 \cdot 80 \\
0.90 \\
1 \cdot 00\end{array}$ & $\begin{array}{l}0.55 \\
0.60 \\
0.65 \\
0.70 \\
0.75 \\
0.80 \\
0.90 \\
1.00 \\
1.10 \\
1.20 \\
1.30 \\
1.40 \\
1.50\end{array}$ & $\begin{array}{l}1.05 \\
1.10 \\
1.15 \\
1.20 \\
1.25 \\
1.30 \\
1.40 \\
1.50 \\
1.60 \\
1.70 \\
1.80 \\
1.90 \\
2.00\end{array}$ & $\begin{array}{l}52 \cdot 4 \\
54 \cdot 5 \\
56 \cdot 5 \\
58 \cdot 3 \\
60 \cdot 0 \\
61 \cdot 5 \\
64 \cdot 3 \\
66 \cdot 7 \\
68 \cdot 9 \\
70 \cdot 6 \\
72 \cdot 3 \\
73 \cdot 7 \\
75 \cdot 0\end{array}$ & $\begin{array}{l}0.997 \\
1.002 \\
1.007 \\
1.011 \\
1.015 \\
1.019 \\
1.025 \\
1.031 \\
1.036 \\
1.040 \\
1.044 \\
1.047 \\
1.050\end{array}$ \\
\hline
\end{tabular}

Method.-Into a $3 \times \frac{1}{2}$-in. test-tube $1 \mathrm{ml}$. of the reference liquid " A" is accurately measured, allowing sufficient time for the pipette to drain properly. One small drop of the urine is added to the liquid by means of a capillary pipette. The urine falls to the bottom of the tube. Monochlorobenzene is added drop by drop from a 2-ml. microburette graduated in $0.01-\mathrm{ml}$. divisions. After the addition of each drop, the liquid in the tube is gently swirled in order to mix the liquids and also to stir up the drop of urine from the bottom of the tube. The behaviour of the drop of urine is observed when the tube is stationary. If it falls again to the bottom of the tube, more monochlorobenzene is added and the swirling and observation repeated. The end-point is reached when the 
drop of urine no longer falls, but remains suspended in the liquid or rises very slowly when the tube is at rest. The volume of monochlorobenzene added is noted, and the specific gravity of the urine is read from the calibration curve.

The swirling movement of the liquid should not be so vigorous that the drop of urine is broken up into very small droplets, as this makes it more difficult to see when the endpoint is reached. With a little practice it is possible to determine the end-point within one small drop of monochlorobenzene, which is equivalent to approximately 0.001 specific gravity.

Errors due to the urine-water dissolving in the organic liquids are negligible because only small volumes, 1 to $2 \mathrm{ml}$., of these are used. There is also the obvious advantage of economy in materials. The used mixtures may be collected in a residues bottle and subsequently recovered by fractional distillation. The boiling points of the two liquids are sufficiently different to permit of their easy purification.

The reference liquids are stable indefinitely.

Results.-Random samples of urine were collected from ward patients. The specific gravity of each specimen was determined by the titration method using one drop. Subsequently, the specific gravity was measured with a urinometer in the bulk of the specimen. Comparison of the results in Table II shows satisfactory agreement between the two methods. The urinometer readings do not represent absolutely correct values, and therefore differences in the results obtained by the two methods must not be ascribed entirely to error in the micro method. It will be seen below that these results may be on opposite sides of the true value.

TABLE II

Comparison of Specific Gravity Readings of Urine Samples by Micro-titration AND BY URINOMETER

\begin{tabular}{c|c|c|c}
\hline $\begin{array}{c}\text { Specimen } \\
\text { No. }\end{array}$ & $\begin{array}{c}\text { Titration (ml. of } \\
\text { Monochlorobenzene) }\end{array}$ & $\begin{array}{c}\text { Specific Gravity Reading } \\
\text { from Calibration Curve }\end{array}$ & $\begin{array}{c}\text { Specific Gravity } \\
\text { Reading by Urinometer }\end{array}$ \\
\hline 1 & 0.24 & 1.014 & 1.014 \\
2 & 0.31 & 1.020 & 1.019 \\
3 & 0.32 & 1.020 & 1.017 \\
4 & 0.44 & 1.027 & 1.023 \\
5 & $0 \cdot 28$ & 1.017 & 1.018 \\
6 & 0.26 & 1.016 & 1.016 \\
7 & 0.31 & 1.020 & 1.018 \\
8 & 0.89 & 1.047 & 1.043 \\
9 & 0.20 & 1.011 & 1.016 \\
10 & 0.27 & 1.017 & 1.017 \\
11 & 0.30 & 1.019 & 1.010 \\
12 & $0 \cdot 17$ & 1.009 & 1.016 \\
13 & 0.32 & 1.020 & 1.012 \\
14 & $0 \cdot 19$ & 1.010 & 1.016 \\
15 & 0.23 & & \\
\hline
\end{tabular}

In order to test the accuracy of the method over the whole range of specific gravities likely to be encountered in urines, salt solutions were used. The specific gravities of a series of solutions ranging in concentration from 1 to $7 \%$ of sodium chloride in distilled water were measured by three methods for comparison ; first, the micro-titration method as described, secondly by urinometer, and thirdly by a gravimetric method. For the last method, a sample of the solution was accurately measured in a $25-\mathrm{ml}$. pipette, transferred to a tared weighing bottle, and weighed on an analytical balance to the nearest 
$0.0005 \mathrm{~g}$. Using the same pipette, cleaned and dried, the same volume of distilled water was weighed in a similar manner. The specific gravity of the salt solution was calculated by dividing the weight of the sample by the weight of the same volume of water. In this way, possible errors in the calibration of the pipette are compensated. This method is the most accurate of the three used and can be taken as a reliable basis for comparison.

The results in Table III show that the micro-titration method is reliable within \pm 0.002 unit of specific gravity over the whole range which is likely to be found for urine, from 1.006 to 1.047 .

Very occasionally, urines with very high specific gravity have been received from patients who have had "uroselectan." The actual values of specific gravity of these urines have no clinical significance, and it has not been considered advisable to alter the range of the method to include these.

All values of specific gravity in this paper are for a room temperature of $20^{\circ} \mathrm{C}$.

TABLE III

Comparison of Results for the Determination of the Specific Gravities of Salt SOLUTIONS BY THREE METHODJ

\begin{tabular}{|c|c|c|c|c|}
\hline \multirow{2}{*}{$\begin{array}{c}\text { Concentration } \\
\text { of Sodium } \\
\text { Chloride } \\
(\%)\end{array}$} & \multicolumn{2}{|c|}{ Micro-titration Method } & \multirow{2}{*}{$\begin{array}{l}\text { Urinometer } \\
\text { Method } \\
\text { (Specific } \\
\text { Gravity) }\end{array}$} & \multirow{2}{*}{$\begin{array}{l}\text { Gravimetric } \\
\text { Method } \\
\text { (Specific } \\
\text { Gravity) }\end{array}$} \\
\hline & $\begin{array}{l}\text { Titration } \\
\text { (ml.) }\end{array}$ & $\begin{array}{l}\text { Specific } \\
\text { Gravity }\end{array}$ & & \\
\hline $\begin{array}{l}1 \cdot 0 \\
2 \cdot 0 \\
3 \cdot 0 \\
4 \cdot 0 \\
5 \cdot 0 \\
6 \cdot 0 \\
7 \cdot 0\end{array}$ & $\begin{array}{l}0.15 \\
0.20 \\
0.29 \\
0.46 \\
0.53 \\
0.79 \\
0.86\end{array}$ & $\begin{array}{l}1.007 \\
1.011 \\
1.018 \\
1.028 \\
1.032 \\
1.044 \\
1.046\end{array}$ & $\begin{array}{l}1.006 \\
1.015 \\
1.020 \\
1.028 \\
1.033 \\
1.043 \\
1.045\end{array}$ & $\begin{array}{l}1.0060 \\
1.0130 \\
1.0203 \\
1.0268 \\
1.0331 \\
1.0433 \\
1.0467\end{array}$ \\
\hline
\end{tabular}

\section{Summary}

A simple titration method for the determination of the specific gravity of urine when only one drop is available is described.

One drop of urine is added to a small volume of a mixture of benzene and monochlorobenzene, in which it sinks. The composition of the mixture is altered by titration with monochlorobenzene until the urine floats in equilibrium. The specific gravity of the urine is read from a calibration curve.

Results are given to show that the method is reliable within 0.002 unit of specific gravity over the range 1.006 to 1.047 .

\section{REFERENCES}

Dukes, C. E. (1939). Urine : Examination and Clinical Interpretation, p. 18. London.

Monroe, L., and Hopper, J. (1946). J. Lab. clin. Med., 31, 934. 